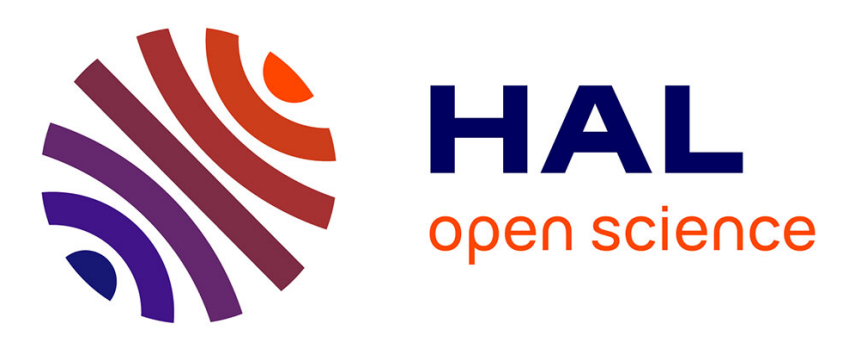

\title{
Sexuality and fertility outcomes following hand-sewn versus stapled ileal pouch anal anastomosis for ulcerative colitis
}

Yann Harnoy, Véronique Desfourneaux, Guillaume Bouguen, Michel Rayar, B. Meunier, Laurent Siproudhis, Karim Boudjema, Laurent Sulpice

\section{To cite this version:}

Yann Harnoy, Véronique Desfourneaux, Guillaume Bouguen, Michel Rayar, B. Meunier, et al.. Sexuality and fertility outcomes following hand-sewn versus stapled ileal pouch anal anastomosis for ulcerative colitis. Journal of Surgical Research, 2016, 200 (1), pp.66-72. 10.1016/j.jss.2015.06.054 . hal-01174213

HAL Id: hal-01174213

https://hal-univ-rennes1.archives-ouvertes.fr/hal-01174213

Submitted on 22 Sep 2015

HAL is a multi-disciplinary open access archive for the deposit and dissemination of scientific research documents, whether they are published or not. The documents may come from teaching and research institutions in France or abroad, or from public or private research centers.
L'archive ouverte pluridisciplinaire HAL, est destinée au dépôt et à la diffusion de documents scientifiques de niveau recherche, publiés ou non, émanant des établissements d'enseignement et de recherche français ou étrangers, des laboratoires publics ou privés. 
Sexuality and fertility outcomes following hand-sewn versus stapled ileal pouch anal anastomosis for ulcerative colitis.

Harnoy Y, MD ${ }^{1}$, Desfourneaux V, MD ${ }^{1}$, Bouguen $\mathrm{G}, \mathrm{MD}^{2,3}$, Rayar M, MD ${ }^{1}$, Meunier B, $\mathrm{MD}^{1}$, Siproudhis L, MD.PhD ${ }^{2}$, Boudjema K, MD.PhD ${ }^{1,3}$ and Sulpice L, MD.PhD ${ }^{1,3}$

${ }^{1}$ Service de Chirurgie Hépatobiliaire et Digestive, Hôpital Pontchaillou, Centre Hospitalier Universitaire, Université de Rennes 1, Rennes, France

${ }^{2}$ Service des Maladies de 1'Appareil Digestif, Hôpital Pontchaillou, Centre Hospitalier Universitaire, Université de Rennes 1, Rennes, France

${ }^{3}$ INSERM, UMR991. Foie, métabolisme et cancer. Université de Rennes 1, Rennes, France Running Title: sexuality and fertility outcomes after IPAA

Correspondence:

Doctor Laurent Sulpice, Service de Chirurgie Hépatobiliaire et Digestive, Hôpital Pontchaillou, Centre Hospitalier Universitaire, Université de Rennes 1, Rennes, France.

Telephone: + 33299284265 Fax: + 33299284129

Email: laurent.sulpice@,chu-rennes.fr

Conflicts of interest: The authors have no conflicts of interest to declare

Funding: The study received no external support

Author contributions:

YH conceived and designed study, undertook the analysis and interpretation of data, and wrote and finalized the manuscript. VD, GB, MR collected data and provided the statistical analysis. BM, LS analyzed and interpreted the data, and revised the manuscript. KB and LS revised the manuscript and gave final approval for publication. 


\section{ABSTRACT}

Background: Ileal pouch anal anastomosis (IPAA) may alter sexuality and fertility in women. The laparoscopic approach seems to reduce infertility rates in women after IPAA. However, the impact of hand-sewn versus stapled IPAA on sexuality and fertility has never been assessed in patients with ulcerative colitis (UC). The objective of this study was to analyse the impact of the IPAA technique on sexuality and fertility in UC.

Methods: All UC patients who underwent an IPAA between May 1996 and April 2011 were included. The patients answered mailed questionnaires including sexuality validated questionnaires and fertility questionnaires. The risk factors of sexual dysfunction were explored.

Results: A total of 135 patients were included. Eighty-eight patients (65\%) answered the questionnaires. Their mean age and follow-up were $37.2 \pm 13.4$ years and $109.7 \pm 57.5$ months. The rates of female and male sexual dysfunction were $50 \%$ and $29 \%$, respectively. Intestinal transit disorders were identified as risk factors in both men and women, and anastomotic stricture in women sexual dysfunction, in univariate analyses. The IPAA technique did not impact sexual function in women but there was a trend for less erectile dysfunction following hand-sewn IPAA $(16.7 \%$ vs $44.4 \%)$. The fertility rate was $47 \%$ in women and $75 \%$ in men, with a trend for a better fertility in women after hand-sewn IPAA $(\mathrm{p}=0.07)$.

Conclusion: In this preliminary study, the hand-sewn or stapled IPAA technique did not impact the sexuality or fertility outcomes of UC patients, but there was a trend for better female fertility and male erectile function following hand-sewn IPAA. Intestinal transit disorders contributed to male and female sexual dysfunction after IPAA.

Keywords: sexuality, fertility, ileal pouch anal anastomosis, proctocolectomy, ulcerative colitis. 


\section{INTRODUCTION}

Ulcerative colitis (UC) is a chronic inflammatory bowel disease (IBD) affecting the mucosa of the rectum and the colon. Total proctocolectomy is indicated in UC patients for medically refractory colitis, acute severe colitis, rectal stenosis and colorectal dysplasia or cancer [1]. Restorative proctocolectomy with ileal pouch anal anastomosis (IPAA), was first described by Parks and Nicholls in 1978 [2], and it is currently the gold standard for the surgical management of UC patients. IPAA functional outcomes and quality of life (QOL), as well as post-operative complications (e.g., pouchitis, small bowel obstruction and pouch failure) have already been extensively studied [3].

Likewise, the type of IPAA, pouch conformation or surgical access have been studied and compared. Functional outcomes between hand-sewn IPAAs and stapled IPAAs have provided variable results, mainly depending on the underlying disease and the type of pouch conformation [4,5]. The ileal J-pouch conformation [6] has been shown to provide better functional outcomes than the S-pouch conformation, and is easier and more rapid to perform than the W-pouch conformation [7-12]. Compared to laparotomy, laparoscopic IPAA has been shown to be associated with fewer long-term complications $[13,14]$ and lower infertility rates in women $[15,16]$. Nevertheless, very few studies have focused on the sexuality and fertility outcomes after IPAA, and none have analysed the impact of the ileo-anal anastomosis technique.

The objective of the present study was to compare the sexual and fertility outcomes in women and men afflicted by UC after IPAA with J-pouch conformation, either hand-sewn or stapled.

\section{PATIENTS AND METHODS}

\subsection{Study population}

A retrospective analysis from a prospective database was undertaken, including all patients who had an initial diagnosis of UC that was treated with a proctocolectomy with IPAA 
performed at a tertiary colorectal surgery referral centre between 1 May 1996 and 30 April 2011. The study protocol was approved by the institutional review board.

Demographic data included the following: gender, age at UC diagnosis, age, body mass index, smoking status at the time of IPAA and any medical history that could have impacted the functional results of IPAA such as abdominal surgery (excluding a prior subtotal colectomy for acute UC), and gynaecologic or obstetric surgery in women. Perioperative data included the following: the indication for surgery, i.e., acute severe colitis, refractory colitis to steroids and/or to immunosuppressant drugs, rectal stenosis, and dysplasia and/or cancer; the type of surgical approach, i.e., 3-stage procedures, laparoscopic approach, conversion to open surgery, anorectal eversion, mesorectal conservation, as well as confection of diverting ileostomy.

Postoperative data included an assessment of mortality at 30 days and post-operative morbidity.

\subsection{Assessment of sexuality and fertility outcomes}

To analyze the sexuality and fertility outcomes, questionnaires were sent to patients on 15 April 2013. The Female Sexual Function Index (FSFI) was used to assess the sexual health of women $[17,18]$ and the International Index of Erectile Function (IIEF-5) was used to assess the sexual health of men [19]. Fertility questionnaires were sent to all patients (Supplementary files). For women, the fertility outcome after IPAA was only assessed for those of childbearing age. The childbearing age was defined as an age cutoff from 15 to 45 years old. Female sexual dysfunction was defined as an FSFI score $\leq 26$ [18]. Male sexual dysfunction was defined as mild to severe erectile dysfunction corresponding to an IEEF-5 score $\leq 21$ [19]. 
Female fertility was defined as the ability to conceive with regular unprotected intercourse and was confirmed through an ultrasound scan of any on-going or past pregnancies (including abortions, extra-uterine pregnancies and miscarriages).

Male fertility was defined as the ability to conceive with regular unprotected intercourse and confirmed by the female partner's ultrasound scan of any on-going or past pregnancies (including abortions, extra-uterine pregnancies and miscarriages).

\subsection{Surgical techniques}

All IPAA operations were performed by senior surgeons following standard procedures $[6,20$ 23]. Open IPAA was performed through a midline periumbilical incision. Laparoscopic IPAA was performed using 5 to 6 laparoscopic ports (5-12mm). In both approaches, colon mobilisation and vascular ligations were performed using standardised techniques and rectal dissection through the mesorectum was performed close to the rectal wall, preserving pelvic innervations. Patients with rectal cancer or narrow pelvises underwent total mesorectum excision (TME). Two distal rectal section techniques were performed depending on the surgeon's preferences: intra-abdominal rectal transection to the pelvic floor with an articulated linear stapler, or anorectal eversion and rectal transection close to the dentate line with a linear stapler [20]. Ileal pouch construction was always performed using a J-pouch [6], and stapled through the midline incision for open technique [21] or through the site of the future ileostomy in the right lower quadrant for the laparoscopic technique. IPAA was either hand-sewn to the dentate line with one layer of interrupted 4.0 resorbable sutures or stapled according to the double staple line technique after insertion of a 29-mm circular stapler (EEA, $\mathrm{CDH}$, PCEA or ILS) through the anus [22]. A pelvic drain was systematically left close to the anastomosis.

Five patients were operated for an indication of cancer but six patients of the cohort presented a cancer on the pathological findings. Cancers were located in the right colon $(n=3)$ and in the 
rectum $(n=3)$. According to French guidelines for colon and rectum cancer therapy regarding the TNM classification, none of the patients were excluded from analyses because none received an adjuvant or neoadjuvant therapy (3,2 and 1 patients were pTisN0M0R0, pT2N0M0R0, and pT3N0M0R0, respectively).

\subsection{Statistical analysis}

Patients with stapled IPAA surgeries were compared to patients with hand-sewn IPAA surgeries to determine differences in the sexual and fertility outcomes of these patient groups. Categorical data were reported as percentages. Quantitative variables were reported as mean \pm standard deviation. Categorical data were compared using the Fisher exact test or the Chisquare test. Quantitative variables were compared using the Mann-Whitney test. The tests were always 2-sided, and results with a p-value $<0.05$ were considered statistically significant. Data were analysed using the software GraphPadPrism 5 for Windows.

Risk factors for male and female sexual dysfunction were evaluated only through univariate. A p value $<0.05$ was considered statistically significant. Univariate analyses were performed using the software Statview (SAS) 5.0 version for Windows. The small sample size of the present cohort did not allow to perform a relevant multivariate analysis.

\section{RESULTS}

\subsection{Demographic and operative data}

In the entire cohort, 135 patients underwent a primary IPAA for initial diagnosis of UC within the 180 -month study period. The mean age was $37 \pm 12$ years. The male/female ratio was 0.85 (62/73). Mean follow-up time was $99 \pm 60$ months. None patient with a diagnosis of cancer received a neo-adjuvant or an adjuvant therapy. IPAA procedures were either hand-sewn or stapled in 69 and 66 patients, respectively. IPAAs were mainly stapled in patients who had anorectal eversion (78\%), and IPAAs were mainly hand-sewn in patients who underwent the laparoscopic approach (71\%). 
As shown in Figure 1 and Table 1, 88 patients (65\%) answered the questionnaires. Table 1 reports the comparison of the demographic and operative data of the entire cohort and the responders to the questionnaires. There were no differences except for the laparoscopic approach.

In the responder group, a prior colectomy was performed in 65 patients $(73.9 \%)$. The laparoscopic approach was performed in 35 cases $(39.8 \%)$ and conversion to open surgery was necessary in 10 cases (29\%). Total mesorectum excision was performed in 5 cases (5.7\%). Anorectal eversion was performed in 42 cases (47.8\%). Temporary diverting ileostomy was performed routinely. Only 4 patients did not have ileostomy due to technical difficulties during the surgery.

\subsection{Sexual dysfunction and fertility in women}

Table 2 reports the results of the FSFI questionnaire completed by the female patients. Forty women $(55 \%)$ replied and the mean score was of $24 \pm 9$. Twenty women (50\%) reported sexual dysfunction (FSFI score $\leq 26)$ including 4 women $(10 \%)$ with no sexual activity. Five women returned a blank questionnaire saying that they were too old to engage in sexual activity ( 2 cases), or refusing to answer such personal questions ( 3 cases). The type of anastomosis had no impact on sexual dysfunction occurrence (table 3). Anastomotic stricture and intestinal transit disorders (night seepage, stool frequency $\geq 5$ / day, night pad use) were identified as risk factors for female dysfunction in univariate analysis.

Forty-three women (59\%) replied to the fertility questionnaire (Table 4). Thirty-one $(72 \%)$ already had children before the IPAA procedure. After he IPAA procedure, 33 women (77\%) were of childbearing age, 15 (46\%) of whom had pregnancy desires and had tried to conceive. Seven women (50\%) became mothers after the IPAA procedure. Two women had to resort to medically assisted procreation (MAP) after undergoing the IPAA procedure and 1 woman had twins (from the hand-sewn group). After the IPAA procedure, caesarean section was the 
chosen delivery method for 5 women because their prior IPAA procedure. Regarding female fertility there was a trend for a better fertility after hand-sewn IPAA ( $\mathrm{p}=0.07$, not significant).

\subsection{Sexual dysfunction and fertility in men}

Table 5 reports the results of the IEEF- 5 questionnaire in the male population. Forty-two men (68\%) completed the IIEF-5 questionnaire with a mean score of $21 \pm 6$. Twelve men (29\%) were evaluated as suffering from moderate to severe erectile dysfunction (IIEF-5 score $\leq 21$ ). In this subgroup, 2 men did not engage in sexual activity. The type of anastomosis had no impact on sexual dysfunction occurrence and night seepage was the only risk factor of male sexual dysfunction detected in univariate analysis $(\mathrm{p}=0.019$; table 6$)$.

Among the 40 men (65\%) who replied to the fertility questionnaire (table 7), $25(63 \%)$ were fathers before undergoing the IPAA procedure. Twelve men $(30 \%)$ had fatherhood desires after the IPAA procedures and tried to conceived, and $9(75 \%)$ eventually became fathers. One man had a successful MAP. Two men with fatherhood desires did not yet have a child but were not diagnosed with post-operative infertility.

\section{DISCUSSION}

IPAA is a common surgical procedure in patients with complicated UC. The ileal pouch can either be hand-sewn or stapled. Little is known about the impact of the IPAA technique on the patients' future sexuality and fertility outcomes. The present study analyzed 135 consecutive IPAA for UC cases with a mean follow-up of 8 years and found that hand-sewing and stapling the ileal pouch to the anus had similar impacts on fertility and sexuality outcomes in patients who had undergone IPAA. Validated questionnaires were administered with a response rate of $65 \%$. This response rate corresponds to the usual rate of mail surveys or and may be lower due to the young age of the study population that partly explain that they are more difficult to locate. 
The characteristics and perioperative data of the UC patients who underwent IPAA procedures were similar between the two study groups. However, stapled anastomosis procedures were more frequently performed by laparotomy and with anorectal eversion than hand-sewn anastomosis procedures which were mainly performed in laparoscopically operated patients. However, this may have little impact on patient outcomes because no difference has been clearly shown between the two techniques.

\subsection{Sexuality after IPAA}

The FSFI questionnaire $[17,18]$ analyses every aspect of female sexual function and has been previously used to assess the impact of the IPAA procedure in many studies. The response rate was high as compared to previous studies of the IPAA impact on female sexuality [2427].

In the present study the rate of female sexual dysfunction after IPAA was $50 \%$, results that were in line with the results previously reported by Ogilvie et al. (47\%) [24] and Van Balkom et al. (50\%) [28]. While sexual dysfunction may be related to the risk of nerve damage at the time of rectal dissection, the close anatomical relationship between the vagina and the pouch could partly explain the high rates of female sexual dysfunction reported, compared to male sexual dysfunction.

No difference was found in female sexuality between our two studied groups. Conversely, Cornish et al. showed that the rate of dyspareunia increased from $8 \%$ before to $25 \%$ after IPAA, without any change in sexual satisfaction [29]. These differences may be related to the fact that a validated questionnaire was used in the present study, restricting the subjectivity of the answers, especially concerning an intimate domain. As a matter of fact, five women refused to answer the questionnaire and the fact that it was not anonymous may have had an impact on the reliability of patient answers. 
The current results are similar to previous studies, although the type of anastomosis was not the main end point for comparison [25-27]. Larson et al. found an average FSFI score of 26.7 after IPAA and did not find a difference between the FSFI score of patients who underwent laparotomy compared to laparoscopy [25]. Furthermore, female sexual function improved 12 months after the IPAA procedures compared with preoperative status [26]. The FSFI scores were not different from those of the UC controls [27]. Moreover, no relationship was found between sexual dysfunction after the IPAA procedure and the fear of anal leakage or pouch failure [24]. However in the present study, the univariate analysis showed that fear of anal leakage may have an impact on female sexuality. Compared to the results of the general healthy population described by Rosen et al. [17], the present authors found a lower overall FSFI score and lower results in all areas of the female sexual function.

In the male population, the previously validated IIEF-5 questionnaire [19] was used, although it was an abridged version of the IIEF-15 and analyzed only 1 field of male sexual function, i.e. the erectile function. Erectile dysfunction was found in $25 \%$ of men and was not associated with the anastomosis technique.

Several studies have analyzed the impact of protectomy and IPAA procedures performed for IBD on male sexual function. Erectile dysfunction after an IPAA procedure has been described in 0 to $26 \%$ of patients $[4,25,26,28,30,31-39]$ and retrograde ejaculation in 0 to $19 \%$ of patients [33-40]. Five studies $[25,26,28,34,41]$ assessed male sexual function after AIA using the IIEF-15 questionnaire, which covered five domains: erectile function, orgasm, sexual desire, intercourse satisfaction and overall satisfaction [42].

In the present study, the presence of faecal seepage at night was the only identified risk factor for erectile dysfunction. Obviously, this factor may be related to the psychological effect of night seepage, as observed in women. However one should be aware that the erectile dysfunction and faecal seepage may have a common aetiology. The trend of a better erectile 
function following hand-sewn IPAA, while it was not significant, may be due to the preferential use of anorectal eversion in stapled anastomosis in the present study, which may impair nerve function. However, none of the previous study found this association. The TME procedure, known to have a risk of nerve injury and erectile dysfunction, and performed in men for cancer or narrow pelvis in the present study, was not different between the 2 studied groups.

\subsection{Fertility after IPAA}

The overall rate of infertility was $53 \%$ of the childbearing age population and who attempted to conceive. The present findings showed that there was a trend toward better fertility rates in female patients who underwent the hand-sewn IPAA procedure. However, this observation may be due to the greater use of laparoscopy in the hand-sewn IPAA group. Indeed, two recent studies have shown that fertility rates were higher after laparoscopic IPAA procedures compared to open IPAA procedures $[12,13]$, which may be due to the reduction in scarring and in intraperitoneal and adnexal adhesions. As a matter of fact, in the current study, $75 \%$ of the male patients who underwent IPAA had normal fertility outcomes, regardless the anastomosis technique.

\subsection{Limitations of the study}

As every retrospective study, the present work had some limitations that should be mentioned. First, a comparison between preoperative and postoperative outcomes might improve the relevance of our results. Since the beginning of this work, we changed our policy center and we systematically submitted preoperative and postoperative questionnaires regarding sexuality and fertility. Second, this study was possibly underpowered regarding the number of patients who respond to the questionnaires. However, it is a rare pathology, and we stopped the data collection to assess what the impact was after a 3-year follow-up for the last patients operated. This might impact on the results, specifically on the multivariable analyses which 
could not been performed, and they need to be confirmed in multicentric study. Third, handsewn anastomosis was mainly performed through a laparoscopic approach and without anorectal eversion. This might have impacted the results, specifically on fertility in women regarding previous studies $[12,13]$. Moreover, this could explain the trends that more pregnancies and less erectile dysfunctions were observed following hand-sewn anastomosis, results which could become significant with larger groups. However, none of the previous studies have shown that laparoscopic approach or anorectal eversion could impact sexuality, in men and women, or fertility in men.

In summary, the results of the present preliminary study provide new information on the functional results of IPAA procedures and especially highlight that the type of IPAA procedure affects neither the sexuality nor the fertility outcomes in UC patients. However, there was a trend for better female fertility and erectile function following hand-sewn IPAA. With a long follow-up period, half of women had sexual dysfunction following the IPAA procedure. Fear of anal leakage (night seepage) interfered in male and female sexuality outcomes after the IPAA procedure. Infertility remains high in UC patients after IPAA and affects more women than men.

\section{LEGENDS OF FIGURES AND TABLES}

Figure 1. Distribution of the patients according to the anastomosis technique and to response to questionnaires

Table 1. Ulcerative colitis patients with ileal pouch anal anastomosis: comparison of the characteristics of the entire cohort versus the patients responding to the questionnaires

Table 2. Female sexuality after IPAA for ulcerative colitis: a comparison of hand-sewn versus stapled IPAA 
Table 3. Univariate analyses of risk factors of female sexual dysfunction (score FSFI $\leq 26$ ) after IPAA for ulcerative colitis

Table 4. Female fertility after IPAA for ulcerative colitis: a comparison of hand-sewn versus stapled IPAA

Table 5. Male sexuality after IPAA for ulcerative colitis: a comparison of hand-sewn versus stapled IPAA

Table 6. Univariate analyses of risk factors of mild to severe erectile dysfunction (IIEF-5 score $\leq 21)$ after IPAA for ulcerative colitis

Table 7. Male fertility evaluation after IPAA for ulcerative colitis: hand-sewn versus stapled IPAA

\section{REFERENCES}

[1]. Danese S, Fiocchi C. Ulcerative colitis. N Engl J Med 2011;365:1713-25.

[2]. Parks AG, Nicholls RJ. Proctocolectomy without ileostomy for ulcerative colitis. BMJ $1978 ; 2: 85-8$

[3]. Fazio VW, Kiran RP, Remzi FH, Coffey C, Heneghan HM, Kirat HT, et al. Ileal pouch anal anastomosis: analysis of outcome and quality of life in 3707 Patients. Ann Surg 2013;257:679-85.

[4]. Lovegrove RE, Constantinides VA, Heriot AG, Athanasiou T, Darzi A, Remzi FH, et al. A comparison of hand-sewn versus stapled ileal pouch anal anastomosis (IPAA) following proctocolectomy: a meta-analysis of 4183 patients. Ann Surg 2006;244:18-26.

[5]. Kirat HT, Remzi FH, Kiran RP, Fazio VW. Comparison of outcomes after handsewn versus stapled ileal pouch-anal anastomosis in 3,109 patients. Surgery 2009;146:7239; discussion 729-30. 
[6]. Utsunomiya J, Iwama T, Imajo M, Matsuo S, Sawai S, Yaegashi K, et al. Total colectomy, mucosal proctectomy, and ileoanal anastomosis. Dis Colon Rectum 1980;23:45966.

[7]. Fonkalsrud EW. Total colectomy and endorectal ileal pull-through with internal ileal reservoir for ulcerative colitis. Surg Gynecol Obstet 1980;150:1-8.

[8]. Nicholls RJ, Lubowski DZ. Restorative proctocolectomy: the four loop (W) reservoir. Br J Surg 1987;74:564-6.

[9]. Nicholls RJ, Pezim ME. Restorative proctocolectomy with ileal reservoir for ulcerative colitis and familial adenomatous polyposis: a comparison of three reservoir designs. Br J Surg $1985 ; 72: 470-4$

[10]. McGuire BB, Brannigan AE, O'Connell PR. Ileal pouch-anal anastomosis. Br J Surg 2007;94:812-23.

[11]. Lovegrove RE, Heriot AG, Constantinides V, Tilney HS, Darzi AW, Fazio VW, et al. Meta-analysis of short-term and long-term outcomes of J, W and S ileal reservoirs for restorative proctocolectomy. Colorectal Dis 2007;9:310-20.

[12]. McCormick PH, Guest GD, Clark AJ, Petersen D, Clark DA, Stevenson AR, et al. The ideal ileal-pouch design: a long-term randomized control trial of J- vs W-pouch construction. Dis Colon Rectum 2012;55:1251-7.

[13]. El-Gazzaz GS, Kiran RP, Remzi FH, Hull TL, Geisler DP. Outcomes for case-matched laparoscopically assisted versus open restorative proctocolectomy. Br J Surg 2009;96:522-6. [14]. Larson DW, Cima RR, Dozois EJ, Davies M, Piotrowicz K, Barnes SA, et al. Safety, feasibility, and short-term outcomes of laparoscopic ileal-pouch-anal anastomosis: a single institutional case-matched experience. Ann Surg 2006;243:667-70;discussion 670-2. 
[15]. Bartels SA, D’Hoore A, Cuesta MA, Bensdorp AJ, Lucas C, Bemelman WA. Significantly increased pregnancy rates after laparoscopic restorative proctocolectomy. Ann Surg 2012;256:1045-8.

[16]. Beyer-Berjot L, Maggiori L, Birnbaum D, Lefevre JH, Berdah S, Panis Y. A total laparoscopic approach reduces the infertility rate after ileal pouch-anal anastomosis. Ann Surg $2013 ; 258: 275-82$.

[17]. Rosen R, Brown C, Heiman J, Leiblum S, Meston C, Shabsigh R, et al. The Female Sexual Function Index (FSFI): a multidimensional self-report instrument for the assessment of female sexual function. J Sex Marital Ther 2000;26:191-208.

[18]. Wiegel M, Meston C, Rosen R. The female sexual function index (FSFI): crossvalidation and development of clinical cut-off scores. J Sex Marital Ther 2005;31:1-20.

[19]. Rosen RC, Cappelleri JC, Smith MD, Lipsky J, Peña BM. Development and evaluation of an abridged, 5-item version of the International Index of Erectile Function (IIEF-5) as a diagnostic tool for erectile dysfunction. Int J Impot Res 1999;11:319-26.

[20]. Goligher JC. Eversion technique for distal mucosal proctectomy in ulcerative colitis. A preliminary report. Br J Surg 1984;71:26-8.

[21]. Heald RJ, Allen DR. Stapled ileo-anal anastomosis: a technique to avoid mucosal proctectomy in the ileal pouch operation. Br J Surg 1986;73:571-2.

[22]. Hughes JP, Bauer AR, Bauer CM. Stapling techniques for easy construction of an ileal J-pouch. Am J Surg 1988;155:783-5.

[23]. Thirlby RC. Optimizing results and techniques of mesenteric lengthening in ileal pouchanal anastomosis. Am J Surg 1995;169:499-502.

[24]. Ogilvie JW Jr, Goetz L, Baxter NN, Park J, Minami S, Madoff RD. Female sexual dysfunction after ileal pouch-anal anastomosis. Br J Surg 2008;95:887-92. 
[25]. Larson DW, Davies DM, Dozois EJ, Cima RR, Piotrowicz K, Anderson K, et al. Sexual function, body image and quality of life after laparoscopic and open ileal pouch-anal anastomosis. Dis Colon Rectum 2008;51:392-6.

[26]. Davies RJ, O’Connor BI, Victor C, Macrae HM, Cohen Z, McLeod RS. A prospective evaluation of sexual function and quality of life after ileal pouch-anal anastomosis. Dis Colon Rectum 2008;51:1032-5.

[27]. Cornish J, Wooding K, Tan E, Nicholls RJ, Clark SK, Tekkis PP. Study of Sexual, Urinary, and Fecal Function in Females Following Restorative Proctocolectomy. Inflamm Bowel Dis 2012;18:1601-7.

[28]. Van Balkom KA, Beld MP, Visschers RG, van Gemert WG, Breukink SO. Long-term results after restorative proctocolectomy with ileal pouch-anal anastomosis at a young age. Dis Colon Rectum 2012;55:939-47.

[29]. Cornish JA, Tan E, Teare J, Teoh TG, Rai R, Darzi AW, et al. The effect of restorative proctocolectomy on sexual function, urinary function, fertility, pregnancy and delivery: a systematic review. Dis Colon Rectum 2007;50:1128-38.

[30]. Marcello PW, Roberts PL, Schoetz DJ Jr, Coller JA, Murray JJ, Veidenheimer MC. Long-term results of the ileoanal pouch procedure. Arch Surg 1993;128:500-3; discussion 503-4.

[31]. Tiainen J, Matikainen M, Hiltunen KM. Ileal J-pouch-anal anastomosis, sexual dysfunction, and fertility. Scand J Gastroenterol 1999;34:185-8.

[32]. Hueting WE, Gooszen HG, van Laarhoven CJ. Sexual function and continence after ileo pouch anal anastomosis: a comparison between a meta-analysis and a questionnaire survey. Int J Colorectal Dis 2004;19:215-8.

[33]. Damgaard B, Wettergren A, Kirkegaard P. Social and sexual function following ileal pouch-anal anastomosis. Dis Colon Rectum 1995;38:286-9. 
[34]. Gorgun E, Remzi FH, Montague DK, Connor JT, O’Brien K, Loparo B, et al. Male sexual function improves after ileal pouch anal anastomosis. Colorectal Dis 2005;7:545-50. [35]. Slors FJ, Van Zuijlen PP, Van Dijk GJ. Sexual and bladder dysfunction after total mesorectal excision for benign diseases. Scand J Gastroenterol Suppl 2000;232:48-51.

[36]. Michelassi F, Stella M, Block GE. Prospective assessment of functional results after ileal J pouch-anal restorative proctocolectomy. Arch Surg 1993;128:889-94;discussion 894-5. [37]. Lindsey I, George BD, Kettlewell MG, Mortensen NJ. Impotence after mesorectal and close rectal dissection for inflammatory bowel disease. Dis Colon Rectum 2001;44:831-5.

[38]. Yeager ES, Van Heerden JA. Sexual dysfunction following proctocolectomy and abdominoperineal resection. Ann Surg 1980;191:169-70.

[39]. Bauer JJ, Gelernt IM, Salky B, Kreel I. Sexual dysfunction following proctocolectomy for benign disease of the colon and rectum. Ann Surg 1983;197:363-7.

[40]. Polle SW, Dunker MS, Slors JF, Sprangers MA, Cuesta MA, Gouma DJ, et al. Body image, cosmesis, quality of life, and functionnal outcomes of hand-assisted laparoscopic versus open restorative proctocolectomy: long-term results of a randomized trial. Surg Endosc 2007;21:1301-7.

[41]. Bengtsson J, Lindholm E, Nordgren S, Berndtsson I, Oresland T, Borjesson L. Sexual function after failed ileal pouch-anal anastomosis. J Crohns Colitis 2011;5:407-14.

[42]. Rosen RC, Riley A, Wagner G, Osterloh IH, Kirkpatrick J, Mishra A. The international index of erectile function (IIEF): a multidimensional scale for assessment of erectile dysfunction. Urology 1997;49:822-30. 


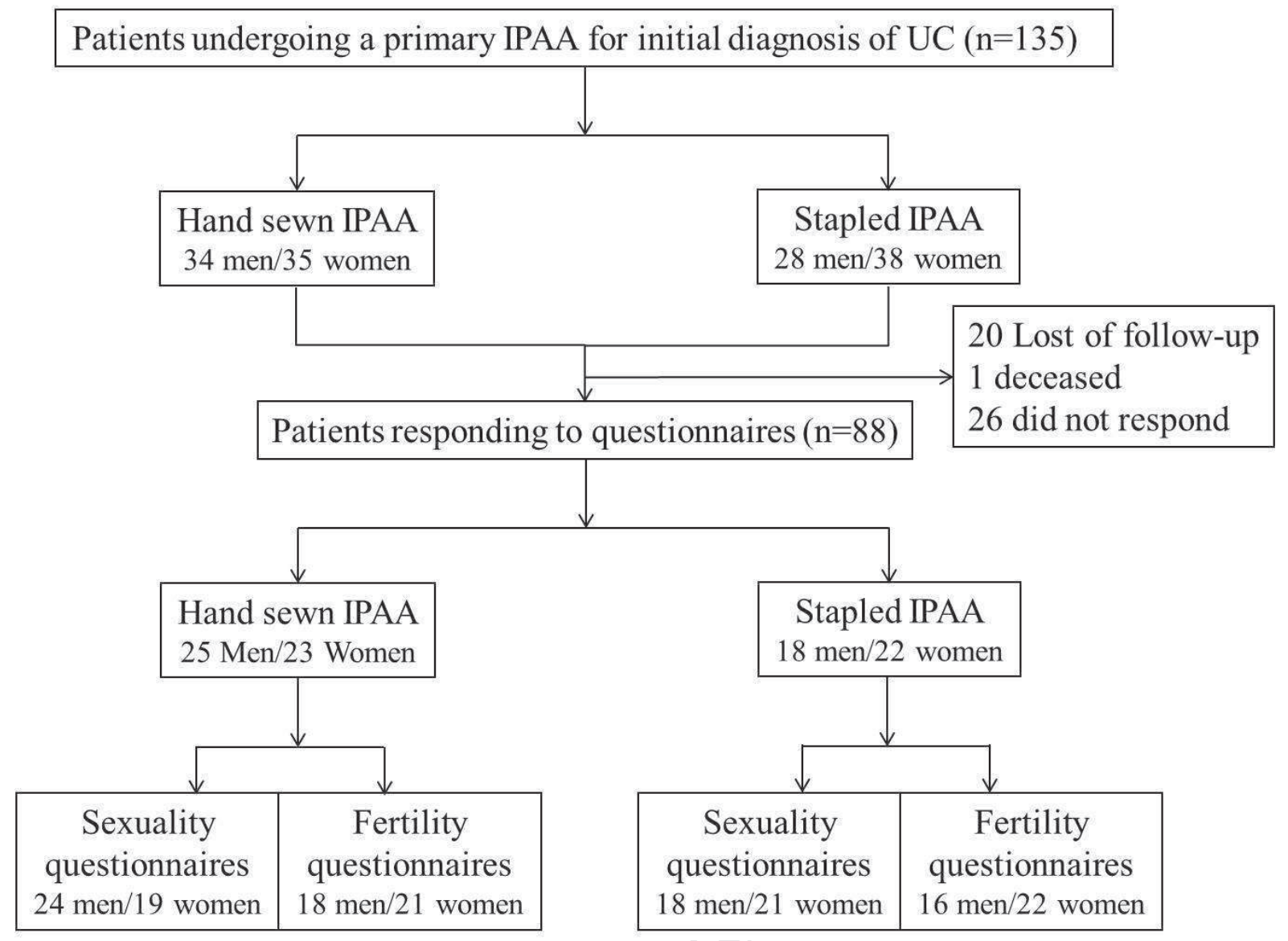

Figure 1. Distribution of the patients according to the anastomosis technique and to response to questionnaires. IPAA, ileal pouch anal anastomosis. UC, ulcerative colitis. 
Table 1. Ulcerative colitis patients with ileal pouch anal anastomosis: comparison of the characteristics of the entire cohort versus the patients responding to the questionnaires

\begin{tabular}{|c|c|c|c|}
\hline & $\begin{array}{l}\text { Entire cohort } \\
\qquad(\mathrm{n}=135)\end{array}$ & $\begin{array}{l}\text { Responders } \\
\quad(n=88)\end{array}$ & $\mathrm{p}$ value \\
\hline Sex ratio $(\mathrm{M} / \mathrm{F})$ & $62 / 73=0.85$ & $43 / 45=0.96$ & 0.67 \\
\hline Age at diagnosis, years $($ mean \pm SD) & $31.3 \pm 12.3$ & $32.4 \pm 13.3$ & 0.52 \\
\hline Age at IPAA, years (mean \pm SD) & $37.1 \pm 12.4$ & $37.2 \pm 13.4$ & 0.91 \\
\hline BMI, kg/m² (mean $\pm \mathrm{SD})$ & $23.7 \pm 3.9$ & $23.6 \pm 3.8$ & 0.88 \\
\hline \multicolumn{4}{|l|}{ Medical history, n (\%) } \\
\hline Past or current smoker & $40(29.6)$ & $28(31.8)$ & 0.69 \\
\hline Abdominal surgery & $27(20)$ & $18(20.5)$ & 0.94 \\
\hline Gynecologic surgery (/women) & $21(28.8)$ & $14(31.1)$ & 0.80 \\
\hline Obstetric history (/women) & $42(57.5)$ & $28(62.2)$ & 0.63 \\
\hline \multicolumn{4}{|l|}{ Indication for surgery, n (\%) } \\
\hline Acute severe colitis & $68(50.4)$ & $47(53.4)$ & 0.65 \\
\hline Refractory colitis to steroids / IS & $38(28.1)$ & $22(25)$ & 0.61 \\
\hline Rectal stenosis & $16(11.9)$ & $9(10.2)$ & 0.71 \\
\hline Dysplasia & $8(5.9)$ & $6(6.8)$ & 0.79 \\
\hline Cancer & $5(3.7)$ & $4(4.5)$ & 0.76 \\
\hline \multicolumn{4}{|l|}{ Surgical approach, n (\%) } \\
\hline Three-stage procedure & $100(74.1)$ & $65(73.9)$ & 0.97 \\
\hline Laparoscopic approach & $35(25.9)$ & $35(39.8)$ & 0.02 \\
\hline Conversion to open surgery & $10(28.6)$ & $10(28.6)$ & 1 \\
\hline Anorectal eversion & $64(47.4)$ & $42(47.8)$ & 0.96 \\
\hline Mesorectal conservation & $126(93.3)$ & $83(94.3)$ & 0.76 \\
\hline Diverting ileostomy & $131(97)$ & $84(95.5)$ & 0.53 \\
\hline Follow-up, months (mean \pm SD) & $98.9 \pm 60.2$ & $109.7 \pm 57.5$ & 0.20 \\
\hline
\end{tabular}

IPAA: ileal pouch anal anastomosis; M/F: male/female; BMI: body mass index; IS: immunosuppressant treatments; SD: standard deviation. 
Table 2. Female sexuality after IPAA for ulcerative colitis: a comparison of hand-sewn versus stapled IPAA

\begin{tabular}{lccc}
\hline & Hand-sewn & Stapled & $\mathrm{p}$ \\
\hline Total number of women, n (\%) & $35(50.7)$ & $38(57.6)$ & 0.49 \\
Sexual questionnaire FSFI & & & \\
$\quad$ Replied to the questionnaire, n (\%) & $19(54.3)$ & $21(55.3)$ & 1 \\
Desire / 6 & $3.32 \pm 1.26$ & $3.14 \pm 1.33$ & 0.68 \\
Arousal / 6 & $3.57 \pm 1.78$ & $4.01 \pm 1.47$ & 0.57 \\
Lubrication / 6 & $4.00 \pm 2.15$ & $4.66 \pm 1.56$ & 0.46 \\
Orgasm / 6 & $3.73 \pm 2.32$ & $4.46 \pm 1.43$ & 0.66 \\
Satisfaction / 6 & $4.38 \pm 1.72$ & $4.67 \pm 1.49$ & 0.66 \\
Pain / 6 & $3.73 \pm 2.19$ & $4.40 \pm 1.86$ & 0.38 \\
Total/ 36 & $22.71 \pm 10.35$ & $25.34 \pm 7.70$ & 0.52 \\
No sexual activity, n (\%) & $3(15.8)$ & $1(4.8)$ & 0.53 \\
Sexual dysfunction, n (\%) & $10(52.6)$ & $10(47.6)$ & 1 \\
\hline IPAA, ileal poun
\end{tabular}

IPAA, ileal pouch anal anastomosis. FSFI, Female Sexual Function Index. Data are reported

as the number of patients (percentage of patients) and as the mean \pm standard deviation. 
Table 3. Univariate analyses of risk factors of female sexual dysfunction (score FSFI $\leq$ 26) after IPAA for ulcerative colitis

\begin{tabular}{lcc}
\hline Risk factors & & $\mathrm{p}$ value \\
\hline Age $\geq 60$ years-old & & 0.56 \\
Stapled anastomosis & & 1 \\
Anorectal eversion & & 0.20 \\
Anastomotic stricture & & 0.032 \\
Night seepage & & 0.011 \\
Stool frequency $\geq 5$ / day & & 0.048 \\
Night pad use & & 0.004 \\
\hline IPAA, ileal pouch anal anastomosis. FSFI, Female & Sexual & Function Index.
\end{tabular}


Table 4. Female fertility after IPAA for ulcerative colitis: a comparison of hand-sewn versus stapled IPAA

\begin{tabular}{lccc}
\hline & Hand-sewn & Stapled & $\mathrm{p}$ \\
\hline $\begin{array}{l}\text { Total number of women, n (\%) } \\
\text { Fertility }\end{array}$ & $35(50.7)$ & $38(57.6)$ & 0.49 \\
$\quad$ Reply to questionnaire, n (\%) & $21(60.0)$ & $22(57.9)$ & 1 \\
$\quad$ Before IPAA & & & \\
$\quad$ Pre-operative diagnosis of infertility, n (\%) & 0 & 0 & 0.51 \\
$\quad$ Maternity, n (\%) & $14(66.7)$ & $17(77.3)$ & \\
After IPAA & & & 0.24 \\
$\quad$ Childbearing age, n (\%) & $14(66.7)$ & $19(86.4)$ & 0.30 \\
$\quad$ Pregnancy desire, n (\%) & $8(57.1)$ & $7(36.8)$ & 0.30 \\
$\quad$ Attempted to conceive, n (\%) & $8(57.1)$ & $7(36.8)$ & 0.07 \\
$\quad$ Pregnancy, n (\%) & $6(75)$ & $1(14.3)$ & 0.51 \\
$\quad$ Resort to MAP due to IPAA, n (\%) & $1(12.5)$ & $1(14.3)$ & 0.61 \\
C-section delivery method, n (\%) & $4(66.7)$ & $1(100)$ & \\
\hline
\end{tabular}

IPAA, ileal pouch anal anastomosis. MAP, medically assisted procreation. Data are reported as the number of patients (percentage of patients) and as the mean \pm standard deviation. 
Table 5. Male sexuality after IPAA for ulcerative colitis: a comparison of hand-sewn versus stapled IPAA

\begin{tabular}{|c|c|c|c|}
\hline & Hand-sewn & Stapled & $\mathrm{p}$ \\
\hline Total number of men, $\mathrm{n}(\%)$ & $34(49.3)$ & $28(42.4)$ & 0.49 \\
\hline \multicolumn{4}{|l|}{ Sexual questionnaire IIEF-5 } \\
\hline Reply to questionnaire, $\mathrm{n}(\%)$ & $24(70.6)$ & $18(64.3)$ & 0.60 \\
\hline Total / 25 & $21.79 \pm 5.74$ & $19.56 \pm 6.37$ & 0.27 \\
\hline \multicolumn{4}{|l|}{ Erectile dysfunction, $\mathrm{n}(\%)$} \\
\hline Severe ED (1-7) & $2(8.3)$ & $1(5.6)$ & 0.80 \\
\hline Moderate ED (8-11) & $0(0)$ & $1(5.6)$ & 0.88 \\
\hline Mild-moderate ED (12-16) & $1(4.2)$ & $3(16.7)$ & 0.40 \\
\hline Mild ED (17-21) & $1(4.2)$ & $3(16.7)$ & 0.40 \\
\hline No ED $(22-25)$ & $20(83.3)$ & $10(55.6)$ & 0.10 \\
\hline No sexual activity, $\mathrm{n}(\%)$ & $1(4.2)$ & $1(5.6)$ & 1 \\
\hline IPAA, ileal pouch anal anastom & International & Erectile Fu & \\
\hline
\end{tabular}


Table 6. Univariate analyses of risk factors of mild to severe erectile dysfunction (IIEF-5 score $\leq 21)$ after IPAA for ulcerative colitis

\begin{tabular}{lc}
\hline Risk factors & $\mathrm{p}$ value \\
\hline Age $\geq 60$ years old & 0.73 \\
Stapled anastomosis & 0.084 \\
Mesorectal conservation & 0.133 \\
Anorectal eversion & 0.194 \\
Pouchitis & 1 \\
Night seepage & 0.019 \\
\hline IPAA, ileal pouch anal anastomosis. IIEF-5, International Index of Erectile Function.
\end{tabular}


Table 7. Male fertility evaluation after IPAA for ulcerative colitis: hand-sewn versus stapled IPAA

\begin{tabular}{|c|c|c|c|}
\hline & Hand-sewn & Stapled & $\mathrm{p}$ \\
\hline Total number of men, $\mathrm{n}(\%)$ & $34(49.3)$ & $28(42.4)$ & 0.49 \\
\hline \multicolumn{4}{|l|}{ Fertility } \\
\hline Reply to questionnaire, $\mathrm{n}(\%)$ & $24(70.6)$ & $16(57.1)$ & 0.30 \\
\hline \multicolumn{4}{|l|}{ Before IPAA } \\
\hline $\begin{array}{l}\text { Pre-operative diagnosis of } \\
\text { infertility, } \mathrm{n}(\%)\end{array}$ & 0 & 0 & - \\
\hline Fatherhood, n (\%) & $15(62.5)$ & $10(62.5)$ & 1 \\
\hline \multicolumn{4}{|l|}{ After IPAA } \\
\hline Attempted to conceive, $\mathrm{n}(\%)$ & $8(33.3)$ & $4(25.0)$ & 0.83 \\
\hline $\begin{array}{l}\text { Fatherhood (/attempted to } \\
\text { conceive), } \mathrm{n}(\%)\end{array}$ & $5(62.5)$ & $4(100)$ & 0.48 \\
\hline $\begin{array}{l}\text { Resort to MAP due to IPAA, } n \\
(\%)\end{array}$ & $1(12.5)$ & $0(0)$ & - \\
\hline
\end{tabular}

IPAA, ileal pouch anal anastomosis. MAP, medically assisted procreation. Data are reported as the number of patients (percentage of patients) and as the mean \pm standard deviation. 
SUPPLEMENTARY FILES:

Supplementary file 1. Male Fertility Questionnaire.

1. Fatherhood desire

Before IPAA procedure? $\quad \square$ YES $\square$ NO

After IPAA procedure? $\quad \square$ YES $\square$ NO

Today? $\quad \square$ YES $\quad \square$ NO

A. If yes, did you attempt to conceive children since IPAA? $\square$ YES $\square$ NO

B. If yes, have you had difficulties conceiving a child? $\square$ YES $\square$ NO If yes, why?

C. If yes, are you in a Medically Assisted Procreation Program? $\quad \square$ YES $\quad \square$ NO If yes, which one and where?

2. Did you have children before the IPAA procedure?

YES $\square$ NO

If yes, how many children have you had?

What are their birthdays?

If no, was it due to an infertility diagnosis?

$\square$ YES $\square$ NO

3. Have you had children since the IPAA procedure?

$\square$ YES $\square$ NO

If yes, how many children have you had?

What are their birthdays?

If no, was it due to an infertility diagnosis?

YES $\square$ NO

4. If you had a child since the IPAA procedure, did you have to resort to a MAP program?

$\square$ YES $\square$ NO

If yes, what was the technique? 


\section{Supplementary file 2. Female Fertility Questionnaire}

\section{Pregnancy desire}

Before IPAA procedure?

$\square$ YES $\quad \square$ NO

After IPAA procedure?

YES $\quad \square \mathrm{NO}$

Today?

YES $\quad \square$ NO
A. If yes, did you attempt to conceive children since IPAA?
YES
NO
B. If yes, have you had difficulties conceiving a child?
YES
$\square \mathrm{NO}$

If yes, why?

C. If yes, are you in a Medically Assisted Procreation Program?

YES

$\square \mathrm{NO}$

If yes, which one and where?

\section{Did you have a pregnancy before the IPAA procedure?}

YES

NO

A. If yes, how many pregnancies and children did you have?

B. If yes, could you complete the following?

\begin{tabular}{lcccccc}
\hline Pregnancy & $1^{\text {st }}$ & $2^{\text {nd }}$ & $3^{\text {rd }}$ & $4^{\text {th }}$ & $5^{\text {th }}$ & $6^{\text {th }}$ \\
\hline Childbirth? & $\square$ & $\square$ & $\square$ & $\square$ & $\square$ & $\square$ \\
Abortion? & $\square$ & $\square$ & $\square$ & $\square$ & $\square$ & $\square$ \\
Miscarriage? & $\square$ & $\square$ & $\square$ & $\square$ & $\square$ & $\square$ \\
Extra-uterine pregnancy? & $\square$ & $\square$ & $\square$ & $\square$ & $\square$ & $\square$ \\
Delivery date & $/ /$ & $/ /$ & $/ /$ & $/ /$ & $/ /$ & $/ /$ \\
On-going pregnancy? & $\square$ & $\square$ & $\square$ & $\square$ & $\square$ & $\square$ \\
Unique pregnancy? & $\square$ & $\square$ & $\square$ & $\square$ & $\square$ & $\square$ \\
Gemellar pregnancy (or more)? & $\square$ & $\square$ & $\square$ & $\square$ & $\square$ & $\square$ \\
Vaginal delivery? & $\square$ & $\square$ & $\square$ & $\square$ & $\square$ & $\square$ \\
C section delivery? & $\square$ & $\square$ & $\square$ & $\square$ & $\square$ & $\square$ \\
Episiotomy? & $\square$ & $\square$ & $\square$ & $\square$ & $\square$ & $\square$ \\
Forceps use? & $\square$ & $\square$ & $\square$ & $\square$ & $\square$ & $\square$ \\
\hline
\end{tabular}

C. If no, was it due to an infertility diagnosis?

YES $\square$ NO

3. Have you had a pregnancy since the IPAA procedure? $\square$ YES $\square$ NO

A. If yes, how many pregnancies and children do you have? 
B. If yes, could you complete the following table?

\begin{tabular}{lcccccc}
\hline Pregnancy & $1^{\text {st }}$ & $2^{\text {nd }}$ & $3^{\text {rd }}$ & $4^{\text {th }}$ & $5^{\text {th }}$ & $6^{\text {th }}$ \\
\hline Childbirth? & $\square$ & $\square$ & $\square$ & $\square$ & $\square$ & $\square$ \\
Abortion? & $\square$ & $\square$ & $\square$ & $\square$ & $\square$ & $\square$ \\
Miscarriage ? & $\square$ & $\square$ & $\square$ & $\square$ & $\square$ & $\square$ \\
Extra-uterine pregnancy ? & $\square$ & $\square$ & $\square$ & $\square$ & $\square$ & $\square$ \\
Delivery date & $/ /$ & $/ /$ & $/ /$ & $/ /$ & $/ /$ & $/ /$ \\
Ongoing pregnancy? & $\square$ & $\square$ & $\square$ & $\square$ & $\square$ & $\square$ \\
Unique pregnancy? & $\square$ & $\square$ & $\square$ & $\square$ & $\square$ & $\square$ \\
Gemellar pregnancy (or more) ? & $\square$ & $\square$ & $\square$ & $\square$ & $\square$ & $\square$ \\
Vaginal delivery? & $\square$ & $\square$ & $\square$ & $\square$ & $\square$ & $\square$ \\
C section delivery? & $\square$ & $\square$ & $\square$ & $\square$ & $\square$ & $\square$ \\
Episiotomy? & $\square$ & $\square$ & $\square$ & $\square$ & $\square$ & $\square$ \\
Forceps use? & $\square$ & $\square$ & $\square$ & $\square$ & $\square$ & $\square$ \\
\hline
\end{tabular}

C. If no, was it due to an infertility diagnosis?

YES $\quad \square$ NO

4. If you had a child since the IPAA procedure, did you have to resort to a MAP program?

YES $\square$ NO

If yes, what was the technique?

5. If you have had children since IPAA, did you feel a functional change after delivery

in:

- Urinary emission $\quad \square$ YES $\quad \square$ NO

- Faecal emission $\quad \square$ YES $\square$ NO

- Sexuality $\square$ YES $\square$ NO

- Vaginal pain $\quad \square$ YES $\square$ NO

- Perianal pain $\quad \square$ YES $\quad \square$ NO

If so, could you describe the functional changes that were induced? 